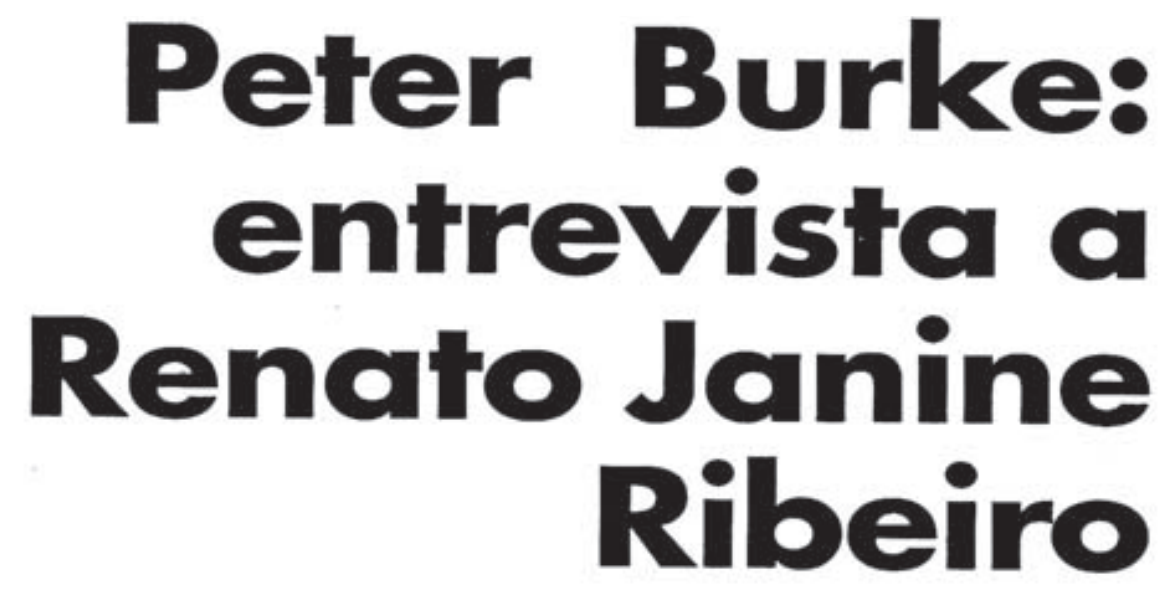

PETER BURKE é professor de História Cultural na Universidade de Cambridge, sendo membro de seu Emmanuel College. Tem vindo com regularidade ao Brasil, sendo casado com uma professora da Faculdade de Educaçăo da USP, Maria Lúcia Pallares Burke, especialista no século XVIII. A entrevista que se segue foi concedida em Cambridge, tratando do livro que acabava de lançar, The Fabrication of Louis XIV Yale University Press, 1992), àquela data já traduzido em holandês.
R.J.R. - Em seu livro, você a certa altura menciona o sociólogo alemão Norbert Elias, falecido recentemente com mais de noventa anos, e que é autor essencial para o estudo do Antigo Regime e de qualquer história dos costumes. Dois de seus livros foram traduzidos no Brasil. Como ele foi desconhecido por muito tempo, talvez pudéssemos começar com você avaliando a contribuiçāo dele para o seu tipo de trabalho.

Peter Burke - Elias teve uma carreira extraordinária, no sentido de que escreveu suas principais obras nos anos $30 \mathrm{e}$ foi completamente ignorado nas décadas de 40,50 e 60. Ensinava sociologia numa universidade inglesa na década de 1950, mas ninguém sabia de sua obra; foi nos anos 70 que sua obra começou a ser reavaliada no mundo de língua alemã, e por extensão na França, mas nos países de fala inglesa ela continuou completamente desconhecida. Foi uma lástima, tanto para os historiadores quanto para os leitores em geral, que seus livros não tenham alcançado a influência merecida tāologosaíram, por volta de 1939; isso, em parte, certamente se deveu à Segunda Guerra Mundial. Um dos pontos importantes de sua obra é que aprendeu muitocom Weber, mastambém comFreud, e assim repensou a sociologia weberiana à luz de muitos elementos psicológicos.

Se abordava um tema que os historiadores haviam estudado, Elias tinha o dom de virá-lo pelo avesso. É o caso de sua estupenda observação segundo a qual não devemos criticar os nobres por gastarem tanto dinheiro, porque era essa a única estratégia racional graças à qual eles podiam conservar-se enquanto nobres. Isso ele ilustra no detalhe concreto, como no caso de um aris- tocrata que dá a seu filho uma soma de dinheiro para gastar, e quando o rapaz lhe diz que nãoo despendeu, opai joga a bolsa pela janela: ele tem que aprender como gastar dinheiro.

Travei conhecimento com ele de forma muito estranha, nos anos 60. Estava lendo um manual sobre história do século XVI, escrito por um professor da Universidade de Oxford, Patrick Gordon Walker. Este, nos anos 40, escreveu um artigo elogiando Norbert Elias; mas logo decidiu que a academia o aborrecia, e partiu para a política. Se não me engano, chegou a Ministro do Interior (1) nos anos 60, no governo trabalhista de Harold Wilson. Era um marxista que teve educação clássica numa boa escola particular, de modo que podia combinar a alta cultura britânica e o intuito de dar uma interpretação sociológica dos assuntos de que tratava. Isso o atraiu para a cultura alemã e em especial para Norbert Elias. Dizia que era importante leroque Elias dizia sobre garfos e lenços (2). Assim foi que me pus a ler sobre garfos e lenços. Isto me deu um enfoque, digamos, antropológico, que permite olhar a cultura mesmo ocidental pelo óculo da estranheza. Assim me interessei pela antropologia, li Evans-Pritchard e outros, antes de ler Elias.

R.J.R. - Você falou no detalhe. Isso talvez seja coisa nova no trabalho do historiador: tomar o detalhe ou a anedota expressiva. É o análogo, no trabalho do filósofo, à importância do aforismo, que localizamos em Nietzsche. No caso do detalhe se toma algo que era desdenhadoe passa aser significativo.

Peter Burke - Mas na verdade temos aqui um processo circular. Os historiadores 
"tradicionais" se interessavam pelos detalhes; houve uma reaçãocontra isso, porparte de outros historiadores que exigiam maior análise e um estudo das coisas mais importantes. O que depois ocorreu foi uma redescoberta do detalhe, já nāo estudadocomo fimemsi, mas na medida em que ilustra algo. Neste segundo sentido, concordo com Aby Warburg, cujo slogan em 1900 era "der lieber Gott steckt im Detail" - frase que acredito ele devesse a Flaubert. Mas ele usava isso contra uma espécie de história praticada na Alemanha em seu tempo, de tendência mais teorética.

Oque importaéque odetalhe seja significativo, odetalhe importante, por assim dizer. A arte toda consiste em encontrar odetalhe que signifique. Éo que os micro-historiadores têm feito: construir um livro inteiro com base em algum detalhe relevante.

\section{R.J.R-Vocêachaque essaarte} de captar odetalhe, para usarmos uma distinção de Pascal, pertence mais ao esprit de finesse ou ao esprit degéométrie?Dizendodeoutromodo, trata-se de uma arte, de uma intuição treinada, ou tem, esse uso do detalhe, uma forte base numa teoria?

Peter Burke-Naturalmente, eu procuraria uma posiçāo mais ou menos a meiocaminhoentre estas alternativas. Consideroque as teorias podem ajudar, mas você nunca conseguirá encontrar os melhores exemplos se nảo se socorrer

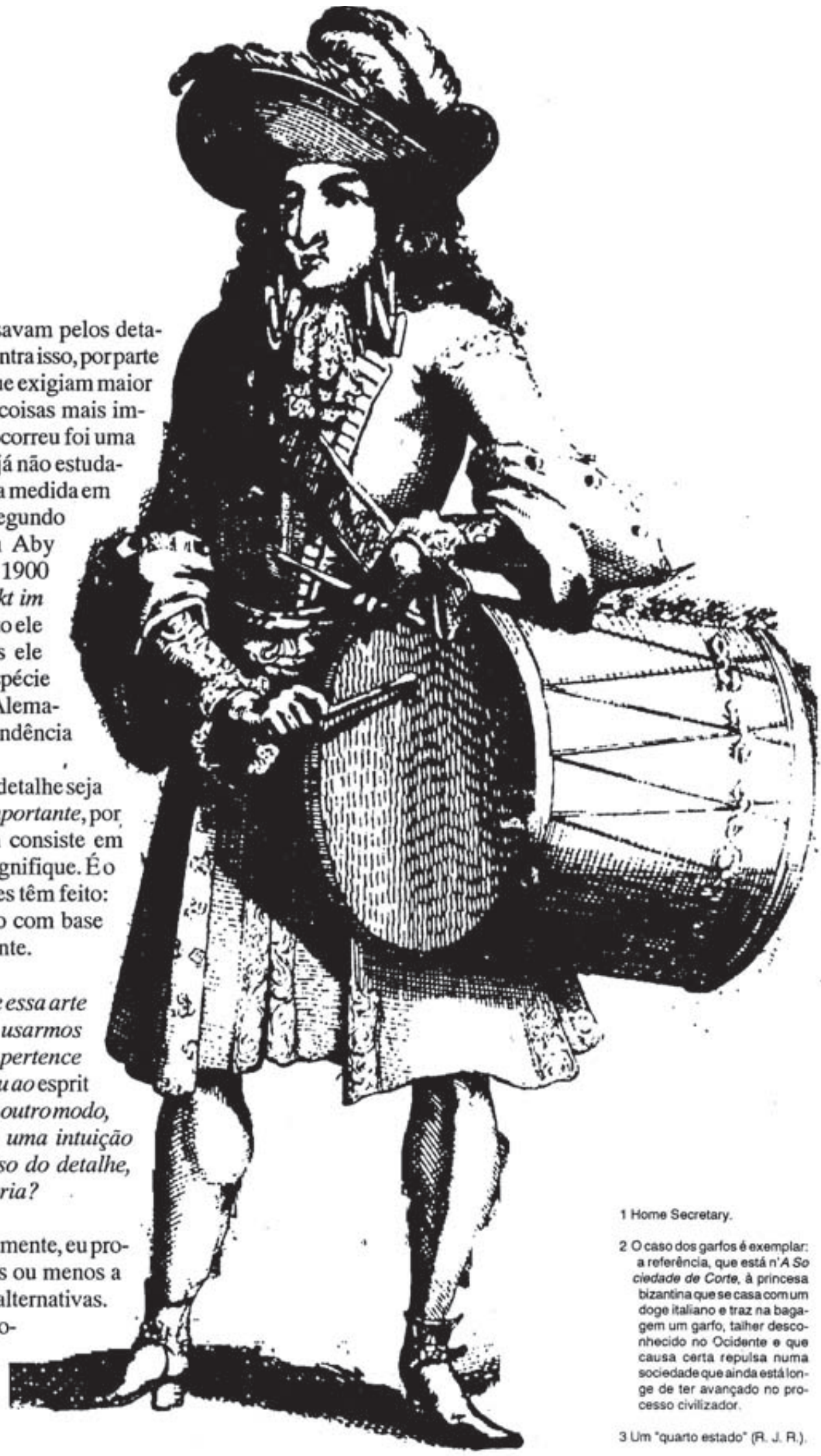

3 Um "quarto estado" (R. J. R.) 
da intuição. Por outro lado, porém, as novas teorias na área da micro-história encorajam os pesquisadores a prestar atenção a esta espécie de detalhe, mais do que costumava ocorrer no passado.

R.J.R. - Quanto ao uso da antropologia, que encontramos em sua obra, assim como na de Georges Duby e outros historiadores?

Peter Burke-Entre os quais incluomeu mestre Keith Thomas, Carlo Ginzburg e vários outros. Bem, aqui parecemos deparar com um paradoxo. Somos historiadores europeus, escrevendosobre a Europa, epara realizar nosso trabalho nos sentimos obrigados a utilizar pesquisadores que trataram de mundos nada europeus: a África, a Ásia, a América. Além disso, para estudar o passado, recorremos a colegas que estudam o presente. Tudo isso parece bastante estranho; e somente se reconhecermos que a necessidade de afastamento é tão grande quanto a de envolvimento com o nosso objeto, é que entenderemos o papel da antropologia enquanto um excelente meio de desfamiliarizar-nos de nossopassado. Uma certa capacidade de surpreender-se perante a etiqueta ou os rituais de coroação praticados em Versalhes é necessária, para que possamosestudá-los devidamente; ora, isto conseguimos lendo sobre Os Nuer, de Evans-Pritchard, ou ainda Negara, o livro em que Clifford Geertz analisa a realeza na ilha de Java. Por exemplo, aprendemos que aquelas pessoas que podiam visitar o palácio de Versalhes deviam, porém, tirar o chapéu na sala em que o rei tomava as refeições, ainda que na ausência do monarca, desde que a mesa estivesse posta, porque num certo sentido a mesa representava o rei; ou que jamais podiam dar as costas a um retrato de Luís, mesmo numa sala vazia, somente podendo afastar-se, portanto, recuando. E mais fácil entender essa espécie de caráter sagrado do rei depois de ler o que Geertz conta da realeza de Java. Masé uma curiosa volta, esta que nos faz entender a monarquia francesa de direito divino por meio da divinização da realeza em Bali.

R.J.R. - Vou aproveitar para levantar a questão da realeza que se exibe, e que se diferencia daquela que se oculta. Na França, Luís XIV éo modelo do monarca que se expōe. Mas em 1972, quando foi coroadoo rei Birendra, do Nepal, nenhum súdito foi admitido à cerimônia. E Luc de Heusch dedica seu Le Roi Ivre oul'Origine del'Etat a um interessante rol de mitos da região do Congo, segundo os quais um monarca de maus modos é deposto por dois príncipes civilizadores, porque ele come em público e eles se ocultam, respeitando a dignidade real, quando vão se alimentar. Será isto apenas um relativismo cultural, ou podemos pensar numa explicação que vá além disso? Por que uma determinada sociedade escolhe exibir a intimidade do rei, suas refeições, mais que isso, suas necessidades, até o sexo do rei, exposto em suas amantes e bastardos, enquantooutra sociedade opta por ocultar tudo isso?

Peter Burke - Esta pergunta é das mais profundas ou difíceis no campo em que nos estamos movendo. Contudo, atrevo-me a dizer que, paradoxalmente, ambas as estratégias, em que pese sua oposição, produzem os mesmos efeitos. Nos dois casos, o resultado consiste em tornar o rei respeitado. Assim, mostrando-se o mínimo possível, ele consegue o máximo de respeito a cada vez que se apresenta a seu povo. E outras pessoas entendem que a melhor estratégia é a de dar-se a ver o maior número possível de vezes: uma constante e cuidadosa representação de si.

Mas a verdadeira questão que você coloca é: por que escolher esta estratégia e não outra? Ora, se nāo posso propor uma resposta completa e definitiva, pelo menos me sinto em condiçōes, como historiador, de dar uma meia resposta, que é a seguinte: num lugar e tempo determinados, pode haver uma tradiçäo determinada. Assim, em meados do século XVII, os reis de Espanha tinham a tradição de se esconderem. Luís $\mathrm{XIV}$, em suas Memórias, zomba um pouco deles. Está deliberadamente construindoseu modo de aparecer em contraste com o rei seu rival - seu tio, seu sogro: Felipe IV de Espanha. Mas, se indagarmos por que Felipe IV escolheu essa estratégia, veremos que Felipe II e III agiram da mesma maneira; minha hipótese-mas é algo que não posso provar, de momento-é que isso tenha algo a ver com as tradições islâmicas presentes na Espanha. Porque seguidas vezes, como cinqüenta anos atrás nos mostraram de Castro, Sánchez e Albornoz, muitíssimo da cultura espanhola parece datar do período dos reinos muçulmanos na Península Ibérica: o modo pelo qual as mulheres se sentavam no chäo, na Espanha, ou em ca- 
deiras, naFrança, constituium desses exemplos. E no caso da França não havia essa tradição islâmica.

Por outro lado, gosto de contrastar Luís com outros monarcas que se exibiam de maneira ainda mais pública, não apenas num ambiente artificial como o de Versalhes, mas na própria praça do mercado, como o rei da Suécia e o da Dinamarca. Eles escolheram esse estilo demótico, já no século XVII. Por que o fizeram? Ora, tratava-se de sociedades camponesas, nas quais existia uma espécie de democracia camponesa. Eram os únicos países da Europa nos quais as assembléias representativas incluíam os camponeses como uma ordem ou estado à parte (3). O rei na praça assim convém a esse tipo de sociedade. O importante é que isso cabe bem mais no restante que conhecemos de sua cultura.

Já a França fica numa situação intermediária. Năo tem a tradiçäo muçulmana do ocultamento, que vemos na Espanha, nem a democracia camponesa da Escandinávia. Luís está conscientemente se situando a meio caminho entre essas duas estratégias.

R.J.R. - Quer dizer que tem sentido a hipótese de que uma grande diferença entre a França e a Espanha se deva à condição feminina: porque pertence à tradição muçulmana of fechamento da mulher entre as paredes ou por trás dos véus. Assim, por exemplo, há quem sugira que a presença da mulherna corte tivesse ume feitocivilizador sobre os homens, contendo-lhes os impulsos agressivos e forçando-os a aprenderem, literalmente, a fazer a corte. Ela era alvo de uma estratégia de agrado, que abrandava e aprimorava as maneiras, e ao mesmo tempoera espectadora, julgandoas condutas dos homens: por todos esses modos, contribuía para que o homem se portasse melhor.

E é importante o fato de que na França amulher tivesse uma presença na corte bem maior do que na Espanha. Você acha que isso pode desempenhar um papel significativona passagemdaetiquetados Habsburgo para os reis franceses?

Peter Burke-Tenhocerteza de que isso é importante. Porque, mais uma vez, uma das maneiras pelas quais Luís XIV desejou dar-se a ver foi abrindo seus aposentos à nobreza de ambos os sexos. Fez assim de Versalhes uma grande festa, na qual as pessoas dançavam, jogavam cartas, conversa- vam, flertavam. É essa a era do salon, ao tempoem que o refinamento da língua francesa estava sendo moldado por grandes anfitriās comoMme.de Rambouillet, epelo menos parte da literatura de corte estava sendo escrita por damas como Mme. de Lafayette, em letra impressa, ou Mme. de Sévigné, ainda em manuscrito. Esse fenômeno nảo conhece paralelo exato na Espanha. Já quanto à Itália, podemos dizer que se coloca a meio caminho; os italianos travaminteressante debate, noséculo XVII: deveriam eles seguir o modelo espanhol ou o francês?

Assim, a idéia que você levantou de dois modelos pode recuar até a Itália da Renascença tardia. Eles tinham vivido sob domínio espanhol, tinham portanto seguido o modelo espanhol, e usavam o modelo francês como uma arma para se libertarem daquela dominação. Não penso que tenham chegado a adotar por completo o modelo espanhol, porque na Itália as mulheres sempre tiveram uma liberdade superior à que teriam na Espanha. Tudo isso tornava as pessoas mais conscientes de si mesmas. Aliás, uma das razões pelas quais considero excitante o século XVII-melhor dizendo, os séculos XVI e XVII - é que as pessoas estavam ficando conscientes de existirem diferentesestilos de conduta. Um livrocomo o Cortesão, de Castiglione, é inconcebível sem a percepçāo de que há diferentes estilos - nacionais e sociais - de comportamento.

R.J.R. - Aproveitando a questão da mulher, podemos falar do serralho, do harém. Você mostrou uma imagem (a figura 62 de seu livro) de Luís como mulherengo - no século XVIII, depois de traduzidas as Mil e Uma Noites para o francês e editadas as Cartas Persas de Montesquieu, a referência ao harém vai ficar muito forte. Conheçoumlivroeditado porvolta de 1790, Le Parcaux Cerfs, que apresenta ofalecido Luís XV como um sultão que se diverte com seu harém. Você acha que essa ligação já existia antes? que otema do harém poderia ser uma forma de acusar o rei de tirano, de déspota?

Peter Burke - Parece bastante provável. Sāo as mesmas pessoas, ou a mesma espécie de pessoas, que zombam de Luís XIV dessasdistintas formas. Acima de tudo, trata-se dos protestantes franceses. Não sāo os únicos, mas são os mais empenhados em 
representá-lo como déspota, porque está eliminando suas liberdades; são eles quem mais se concentra na propaganda contra Luís $\mathrm{XIV}$, associando-o ao Turco. Pela segunda metade do século XVII, está-se tornando um lugar-comum associar ao despotismoo Oriente, e em especial o Turco.

Evidentemente, ninguém acreditava que o rei tivesse, mesmo, um harém. Mas esta era uma forma de desacreditá-lo, de mostrálo mau, tolo, ridículo aos olhos da Europa. Estamosnomomentoem que os Habsburgo se batem contra o Império Otomano; os exércitos turcos cercam a própria cidade de Viena; e nessa ocasiāo-é antes de ser revogadoo edito de Nantes, mas os protestantes já estãosendoperseguidos no reinoda França- que a propaganda protestante apresenta Luís como mais turco que os próprios tur$\cos$. A situaçäo era ideal para os propagandistas hostis ao rei, e eles souberam explorála de forma brilhante. E de fato Luís XIV tinha várias mulheres.

R.J.R.-Outroponto importante em seu livro, explícitona conclusäomas apontado várias vezes antes disso, é a idéia de que não há uma oposição da retórica à nãoretórica, da retórica à verdade ou ciência, mas de que há, na verdade, várias retóricas. Seria possível expandirmos esta idéia para uma questão específica. Você marca as diferenças entre nossa época e a de Luís $X I V$, mas, vendo-se como o poder hoje usa de retóricas, até mesmo as de uma suposta não-retórica, talvez se possa afirmar queo poder atual é mais propriamente demótico (e nãonecessariamente mais democrático) do que o do Antigo Regime. Em outras palavras, este conceito, demótico, desempenharia papel-chave na compreensão de nosso próprio mundo?

Peter Burke - Concordo plenamente com isso. No plano retórico, hoje precisa haver sempre um apelo ao povo, mas que pode ser bastante cínico: pode ser efetuado por pessoas que nada sentem em comum com o povo, que desejam apenas tomar as decisōes em nome dele, etc. Penso que Ronald Reagan constitui bom exemplodisso: primeiro, porque utilizou uma linguagem que se dirigia imediatamente ao povo mais do que vários presidentes que o precederam - mas também, em segundo lugar, mostrou-se que tinha uma corte à sua volta, um estilo de vida que odistinguia e afastava das pessoas comuns, em grau bem maior, por exemplo, do que Jimmy Carter.

O verdadeiro desafio seria escrever um livronãosobre LuísXIVesua retóricaóbvia, mas sobre um sistema político no qual a retórica nāo fosse óbvia - um livro que procurasse desvendá-la. Seria interessante escrever um livro sobre a política americana que não tratasse tanto do modo como se vende um presidente, mas sobretudo da retórica do presidente, e em especial de sua retórica da sinceridade.

R.J.R. - Nos jornais brasileiros, lê-se muito a exortação "chega de retórica". $E$ este é justamente o discurso mais retórico! A denegaçāo da retórica é a forma de retórica mais eficaz em nossos dias.

Peter Burke-Etambém sepoderia fazer um belo estudo da presidência brasileira segundo as formas pelas quais se apresenta. Nos últimos anos, assistindo à televisão brasileira, diverti-me vendo o retrato que aparecia atrás de Collor, quando ele fazia seus pronunciamentos; ou notando a alternância entre uma figura sua extremamente formal, a que não faltavam medalhas, e outra, em que falava à imprensa de peito nu, depois de praticar algum esporte, sem sequer uma camisa. Vê-se a importância que ele dava a transmitir uma impressão de juventude, de energia. Aqui, não posso resistir à comparaçăo com Mussolini, que foi o primeirogovernante a fazer questão de expor-se como esportista ativo, de mostrar que dispunha de energia para estar no poder supremo. É claro que essa comparação nāo implica que tenha havido um empréstimo conceitual de Collor a Mussolini; basta mostrar que a mesma idéia está presente nos dois casos: de que o governante tem de se mostrar jovem e cheio de vigor. É uma forma de legitimidade. Daí que surja um problemaquandose temumpresidentemais idoso, por exemplo, George Bush, que precisa entāo mostrar-se constantemente praticando esportes, até mesmo brincando... Não sei se seu jogging é somente teatral e dura apenas os cem metros que a TV cobre, ou se ele continua correndo, mesmo depois que a câmera parou de filmá-lo. Mas é importante para sua imagem que ele se exiba desta maneira.

R.J.R.-Estaéumaforma delegitimação mais americana que européia.

Peter Burke - De acordo. 


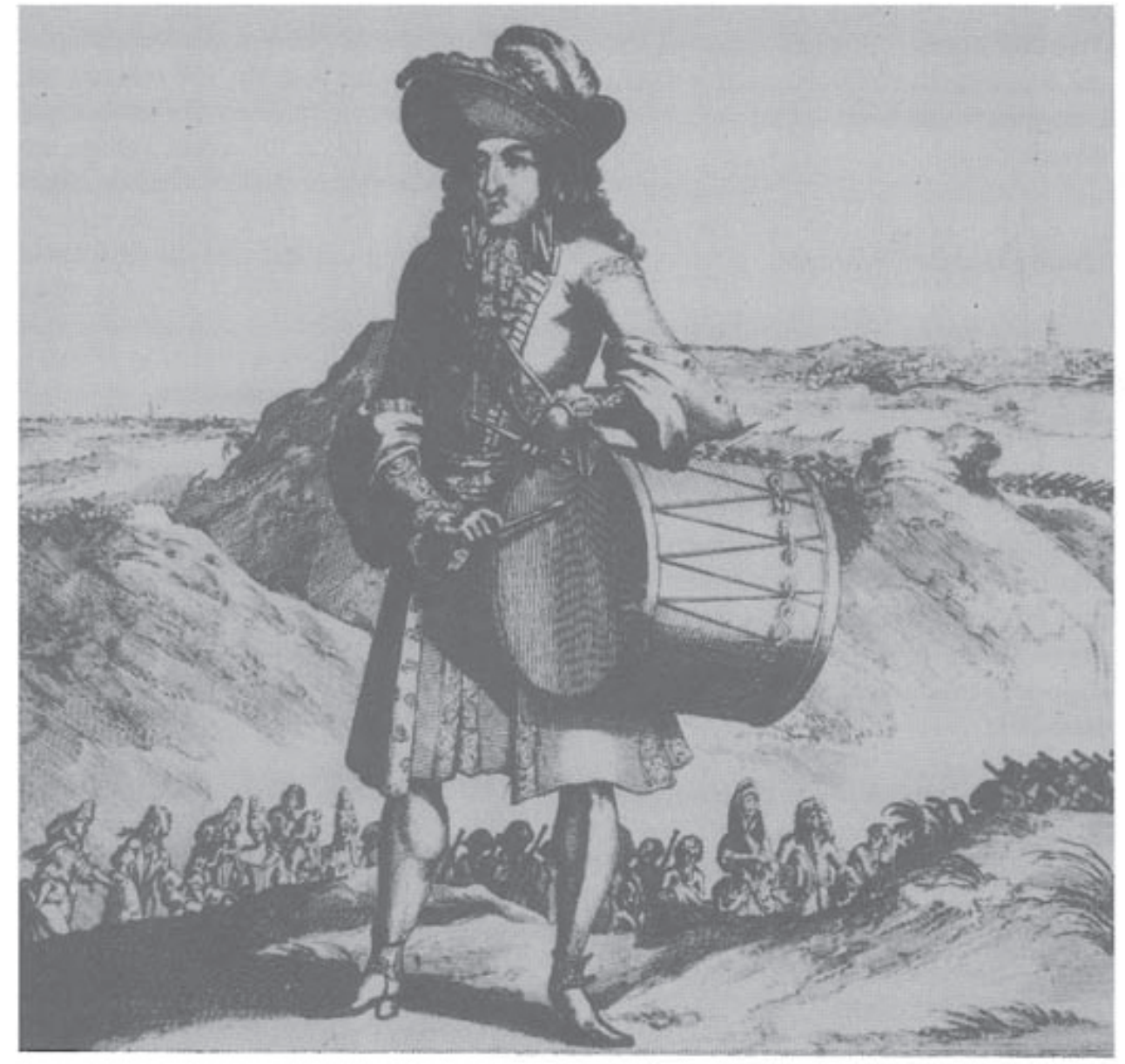

R.J.R. - Você diz que no fim do reinado de Luís XIV a preocupação com a glória parece ser substituída pela preocupação com o povo. Embora este segundo tema já existisse, ganha, agora, em ênfase. Mas podemos dizer que um topos essencial do Antigo Regime consistena idéia doreicomo pai, isto é, como pai amoroso preocupado com seus filhos. Então, por que este segundo tema era mais fraco inicialmente? por que era mais importante, paraojovemLuís $X I V$, falar em glória do que apostar no paternalismo - isso quando o paternalismo era um tema essencial da realeza daquele tempo?

Peter Burke - No Antigo Regime há diversas estratégias possíveis, entre as quais diferentes sociedades ou diferentes governantes podem efetuar sua escolha. Receio dizer algo tradicional, mas estamos lidando com a escolha de Luís XIV, moço, em 1661, que se mostra mais interessado na glória do que no paternalismo. E na outra ponta do reinado temos um monarca velho, mais sábio, e que também conta com outro ministro, Torcy, que pensa de outro modo.
Mas insisto: ambas as escolhas são possíveis, no Antigo Regime.

R.J.R. - Porque Jaime I da Inglaterra fez a opção exatamente oposta: não fala tanto em glória; pensa, sobretudo, em termos do rei como um pai que diz agir para o bem dos súditos.

Peter Burke - Jaime não era de feitio militar; não teria prazer em conquistar a glória nos campos de batalha. Assim, só lhe restava a opção de ser um Salomão. Não poderia ser um Alexandre. Já Luís podia começar o reinado querendo ser Alexandre e, para o fim da vida, cansado, sábio, tornarse Salomão.

R.J.R. - Desta perspectiva, como você veria os reis Stuart? Nenhum deles foi um grande guerreiro. Talvez apenas Jaime II, antes de subir ao trono.

Peter Burke - Não teve tempo, no trono, de mostrar suas capacidades. E suas qualidades militares eram tipicamente britânicas - mais no mar do que em terra. Não
LUIS COMO MULHERENGO GRAVURA ANONIMA DE 1693, MUSEU 
é tāo fácil dramatizar essa parte do papel de rei. Até Jorge II, a tradição dos reis ingleses é envergar o uniforme da marinha e não o do exército.

R.J.R. - Por que você não usou as cartas da Princesa Palatina?

Peter Burke - Por nenhuma razão em princípio. Li-as, escrevi notas, mas acabei usando Saint-Simon em vez dela. Talvez porque ela fale menos do que ele sobre les derrières; como a maior parte do meu livro tratasse das aparências, da produção da máquina propagandística, eu precisava de alguém que falasse dos bastidores do poder. É o caso, também, de Primi Visconti, nobre italiano, que é recebido pelo rei cercadode seus nobres e sentadoem sua chaise percée.

R.J.R. - Outro ponto é a imagem da França enquanto império, tema que vem desde Felipe, o Belo, e que também apareceu na Inglaterra, com Henrique VIII. Há uma tradiçãodotema do império, bemmais antiga; curioso que ela se prolongue ainda em tempos de Luís XIV.

Peter Burke-Depois de Luís, ela perde o sentido, até porque o Império se tornou muito fraco.

Enquanto o Império Romano Germânico teve importância política, a melhor maneira de uma monarquia nacional se afirmar consistia em proclamar-se um império. Assim, o preâmbulo de uma das leis de Henrique VIII afirma: "este reino da Inglaterra é um império". $\underline{\text { Jeffrey }}$ Eltson(?) assinalou isso há bastante tempo, mas foi somente Frances Yates quem mostrou que era preciso olhar também a iconografia e somá-la aos textos para ter uma adequada perspectiva da aspiração imperial, em seu livro Astraea, que trata dessa temática na época da rainha Isabel.

R.J.R. - Já que estamos falando das imagens visuais que sustentam o tema político do Império, você acha que a recorrência de certas imagens ao longo da história decorre de algum inconsciente coletivo ou terá havido uma transmissão das mesmas entre distintas culturas? A imagem do sol, em Augusto, por exemplo. Certas imagens você mostra que foram transmitidas, masas de BizânciotalvezLuís XIV não conhecesse.
Peter Burke - Há um caso bem interessante. Sabemos que em seu reinado um grupo de eruditos estudava Bizâncio, e que chegaram a publicar, no original grego, um corpus de textos daquela sociedade, dedicando-o a Colbert. De modo que, embora se tratasse de um trabalho erudito, havia nele uma intenção política, como se vê na dedicatória ao ministro de Luís XIV, que indica que os autores do trabalho desejariam algum subsídio financeiro. E, como Colbert somente se interessava pelo que tivesse uso prático, é de se pensar que atribuísse alguma serventia ao exemplo bizantino. O curioso, porém, é que eles não publicaram o texto de Constantino Porfirogêneto sobre as cerimônias, que é, de todos, o que mais nos recorda Versalhes. Eos estudiosos em questão tinham perfeita consciência da importância dos ritos em Bizâncio.

Não sei do inconsciente coletivo; mas penso que é possível várias pessoas espalhadas pelo mundo, sem contato entre si, chegarem a uma mesma conclusão: de que o sol constitui bom símbolo para o rei. Do fato de que no Japão e no Peru se pensa assim, nãose deduza necessidade de presumir qualquer relação desses países com a Europa.

R.J.R. - Aqui estamos retomando uma velha discussão, que foi reelaborada, há pouco tempo, por Carlo Ginzburg em sua História Noturna.

Peter Burke - Quando escrevi sobre a cultura popular, perguntei-me quais seriam os limites da européia, quais os limites em que se podem coletar as mesmas folk tales; e pareceu-me que coincidiriam com a Eurásia, incluindo a Índia mas não, por algum motivo, a China e o Japão. As mesmas histórias se reencontram, difundidas talvez da Índia, através do Oriente Médio, até os gregos. Nâosei se os mesmos limites valem ou não para os xamãs, de quem Ginzburg trata.

R.J.R. - Talvez Cinderela, da qual a mais antiga ocorrência se encontra na China no século $I X$, seja uma das raras histórias a vencer está barreira.

Peter Burke - Pode ser; naturalmente, havia contatos entre a India e a China. Mas um número bem maior de histórias se encontra na Índia e no Oriente Médio. 